\title{
Editorial
}

\section{Translating Research into Clinical Practice Skills}

Medical Science strives not only to cure diseases but also to prevent illnesses and promoting health. Being healthy increases our productivity and in turn leads to a prosperous nation. Easier said than done because promoting health requires development of skill in utilizing evidence-based clinical practices. This necessitates basic as well as translational and social research. A clinically applicable treatment entails rigorous experimentation before its benefit to the mankind. It has been debated and suggested that the development of an integrated learning healthcare system will have immense impact on the application of clinically relevant medical knowledge for the benefit of present and future patients (1). Systems medicine which has recently been proposed as a future and primary care centred strategy for healthcare worldwide has been discussed in detail and deliberated but likely to remain incomplete as a foundation for clinical understanding and practice (2).

Adolescents are our wealth for the future. Their proper grooming is crucial and important in different stages of life cycle so that they can be instrumental in bringing societal changes towards the positive development of the mankind. It is important because, firstly, they are naïve and open to new information which can be utilized as an agent of change; secondly, they are seeking independence, which if guided suitably through innovative pedagogical principles, will give them desired freedom and at the same time will make them a conscientious and responsible citizen. If anything that affects them most, it is the technological advances which have a direct bearing on adolescents' behaviour as they find it difficult to imbibe and apply it in their day-to-day practice. Harnessing the technology appropriately for adolescents belonging to Generation $\mathrm{Z}$ will reap rich dividends in the long run. But it is applicable only well when the teenagers are healthy and free from any physical, mental and social encumbrances and disorders.

National Academy of Medical Sciences (India), as per its mandate, fosters and utilizes academic excellence as its resource to meet medical and social goals. This commitment is met by bringing scientists from varied streams onto a common platform of Academy, from where they can promote need-based research more cohesively for the public health applications. Fellows and Members of the Academy bring rich resources of their longstanding work experience and research. Wisdom shared by these eminent people through Orations and Awards will be remembered as a legacy left behind to the younger colleagues. The present issue of the Annals is an effort in this direction.

The opening article highlights the beneficial effects of intake of vegetables in food and importance of fortified food items together with iron supplementation. Dr. Ramachandran in her study on anemia among teenage girls based on the analyses of data from national surveys conducted over last 2 decades found very small improvement in hemoglobin levels as a time trend. Despite national nutritional programs, this trivial improvement may be explained by poor indicators of living standards and overall 
status of the development of the society. She strongly deliberated that Government of India initiative of Double Fortified Salt (DFS) along with increased intake of green vegetables may be economical in reducing prevalence of anemia among adolescent girls and thereby help in improving the health of this important potential workforce of the nation. Even it does not require investment into any costly technology. What it needs is the change in behaviour through well planned educational interventions. The article make us ponder for creating skills in the areas of designing and implementing programs based on Information, Education and Communication (IEC).

Fetal anemia can be lethal unless treated by fetal transfusion. In his Oration in the memory of Dr. JG Jolly delivered during Annual Conference of the National Academy of Medical Sciences (India), NAMSCON 2017 at Amritsar, Brig. (Dr.) Arora presented a detailed account of his work based on managing Rh-alloimmunized pregnancies over a period of 11 years. While reviewing epidemiology, pathophysiology, diagnosis and invasive testing, the Orator went into the details of the procedures for fetal transfusion techniques, thereby saving many infants. The highlight of his study focused on the role of middle cerebral artery-peak systolic velocity (MCA-PSV) using Doppler ultrasound, revealed good correlation with severity of anemia. The favourable neonatal outcome in this study also corroborates with a similar study published elsewhere (3).

Another Oration in the memory of Col. Sangham Lal delivered by Dr. Anil Jain at NAMSCON 2017 at Amritsar reinforces, yet again, the value of Evidence-based Patient Care and also made us ponder- does one research suffice to have evidence towards scientific clinical practice? This article may be able to answer the question to some extent. Dr. Jain, taking an example of tuberculosis of spine, endeavoured to explore questions, accumulating evidences through his continued research in a focused area to find answers for normalising spine and preventing morbidity among his patients. His quest for truth reminisces of a similar study exploring value of medicine-based patient care (4).

For the information of readers, Academy Oration was started in 1965 with a view to inviting one of the senior fellows to share outstanding work done in specific area. Dr. Arvind Bagga, in his Academy Oration delivered at NAMSCON 2017, emphasized the continuing dilemma of children with nephrotic syndrome, a chronic glomerular condition, still with unclear pathogenesis and empirical therapies despite two decades of extensive research. He has shared the recent updates in this review comparing and contrasting various national and international guidelines by different working groups on kidney diseases among children.

Women and children are still a vulnerable group requiring support of the society and target-based provision of healthcare services. Their health in turn builds the healthy society by bridging the gap in the intergenerational cycle. Infant mortality rates in most of the states in India is still very high despite improvement in technologies. Physician still lacks clues to predict preterm birth with certainty and neither have sufficient methods to minimize pregnancy loss which are attributed to multiple factors namely genetic conditions, intrauterine infections or maternal disorders. However, scientific research has vastly improved our understanding of pregnancy and maternal-fetal interactions. In this issue of the Annals, Dr. Kar through his research on Hepatitis E Virus (HEV) reviewed the epidemiology, genotypes and factors responsible for adverse outcome for both mothers and fetus suffering from HEV. He concludes that high viral load and immunological changes together result in poor fetal and maternal 
outcomes among pregnant women with HEV. He has also highlighted that pregnancy outcome also depends on prenatal care and maternal nutrition citing studies from developed nations. These studies further through light on the protective effects of maternal nutrition on acute viral hepatitis during pregnancy.

Most articles in this issue primarily highlight the importance of research for the care towards women and children. A healthy teenage will be transformed into an accomplished adult contributing towards a productive society. From academic point of view, skills can be developed or polished in the cognitive (knowledge), psychomotor (procedure) and attitudinal (emotion) areas. However, in the area of health, research skills are going to have tremendous impact as to how we can deliver healthcare. National Academy of Medical Sciences (India) endeavours to build that skill too with the help of a critical mass ofFellows and Members.

From this issue of Annals, we are adding some new features like Letter to the Editor to bridge the gap in communication between the journal and its readers. We welcome correspondence on articles published in the previous two issues as well as invite comments unrelated to articles emphasizing new information or findings not exceeding 400 words. In this issue of Annals, we share a letter highlighting importance of observation in clinical practice through clinical images.

Editorial Board sincerely hope that Annals will live up to the expectations of the readers and the society which it serves. The official journal is also available free online and does not charge for publication. Scientific contributions from the fellows, members, readers and healthcare professionals on various topics from all streams of biomedical sciences are always welcome but will be subjected to usual review process to enhance the quality and authencity.

Kuldeep Singh Sanjeev Misra

\section{References}

1. Sacristan JA (2015). Clinical research and medical care: towards effective and complete integration. BMC Med Res Methodol 15: 4.

2. Vogt H, Ulvestad E, Eriksen TE, Getz L (2014). Getting personal: can systems medicine integrate scientific and humanistic conceptions of the patient? J Eval Clin Pract 20(6):942-952.

3. Garabedian C, Rakza T, Thomas D, et al (2015). Neonatal outcome after fetal anemia managed by intrauterine transfusion. Eur J Pediatr 174(11):1535-1539.

4. Horwitz RI, Singer BH (2017). Why evidence-based medicine failed in patient care and medicine-based evidence will succeed. JClin Epidemiol 84:14-17. 